\title{
A PERCEPÇÃO DE EFEITOS DE SENTIDO NO DESENVOLVIMENTO DA COMPETÊNCIA LINGUAGEIRA
}

\author{
THE PERCEPTION OF EFFECTS OF MEANING IN THE \\ DEVELOPMENT OF LANGUAGE COMPETENCE
}

\section{Beatriz dos Santos Feres*}

RESUMO: Sob o enfoque da Semiolinguística, este trabalho identifica mecanismos de produção de efeitos de sentido constituintes da competência linguageira, com destaque ao processo de patemização, que pode se basear no emprego de signos organizados em enunciados que testemunham como o mundo é percebido pelos sujeitos em função dos valores atribuídos socialmente aos fenômenos (CHARAUDEAU, 2010), ou pode ser resultado de recursos textuais fundados na iconicidade, por meio da qual se exacerbam as qualidades que unem elementos (FERES, 2006; 2010).

PALAVRAS-CHAVE: Efeitos de sentido. Patemização. Iconicidade.

ABSTRACT: Based on the theoretical background of Semiolinguistics, this paper aims to identify mechanisms of effects of meaning production which constitute language use competence, especially the pathemization process, which can depend on the use of signs organized in utterances. Such utterances testify how the world is perceived by the subjects according to socially attributed values to phenomena (CHARAUDEAU, 2010), or this pathemization process might be the result of textual resources founded in iconicity, whereby they increase the qualities that unite textual elements (FERES, 2006, 2010).

KEYWORDS: Effects of Meaning. Pathemization. Iconicity

\footnotetext{
* Universidade Federal Fluminense (Niterói-RJ). Doutora em Estudos da Linguagem. Professora Adjunta de Língua Portuguesa. Atua no Programa de Pós-graduação em Estudos da Linguagem, na Linha de Pesquisa Teorias do texto, do discurso e da interação e na Especialização em Literatura Infanto-juvenil. Orientadora de doutorado, de mestrado e de especialização. Interesses de pesquisa: leitura e ensino; qualificação implícita; patemização. Autora de Leitura, fruição e ensino: com os meninos de Ziraldo, publicado pela EdUFF em 2011. beatrizferes@id.uff.br
} 


\section{A PERCEPÇÃO dE EFEITOS DE SENTIDO NO DESENVOLVIMENTO DA COMPETÊNCIA LINGUAGEIRA}

\section{“LINGUÍSTICA, PRA QUE TE QUERO!?”}

A relação entre a Linguística e o desenvolvimento da competência linguageira tem se estreitado cada vez mais, seja no campo teórico, seja no aplicado. Pode-se verificar o fato, observando-se a influência de suas correntes no ensino de língua principal e legítimo espaço para o fomento da leitura e da escrita. Se, durante a segunda metade do século XX, verificava-se uma forte ascendência do Estruturalismo nas atividades escolares de língua materna (revelada, sobretudo, em uma pedagogia conteudista que, quase sempre, enfatizou o estudo da análise sintática), na passagem para o século seguinte, houve um investimento crescente em métodos mais reflexivos, baseados em pressupostos orientados pela Linguística de Texto e pelas Teorias do Discurso, privilegiando-se o trabalho com a língua manifesta em enunciados como meio para se alcançar a proficiência linguística.

Uma prova desse estreitamento é a base teórica dos Parâmetros Curriculares Nacionais (PCN), lançados em 1997-1998, que apregoam a centralidade do texto e dos gêneros discursivos no trato de enunciados orais ou escritos com o objetivo de se desenvolver a competência linguageira. Fiorin (1997, p.9) já afirmava, antes do lançamento dos PCN, que "o compromisso primeiro do professor é auxiliar o aluno a tornar-se um leitor autônomo e um produtor competente de textos" e, para tal, a escola deveria se procupar menos com a metalinguagem e mais com o funcionamento da linguagem, trabalhando o texto de maneira mais eficaz, não mais como "uma grande frase ou uma soma de frases", ensinando a estruturar o período, e exigindo que os alunos produzissem textos.

Nos últimos trinta anos, muitas pesquisas têm oferecido subsídios para a aplicação de teorias linguísticas na prática pedagógica. Estudiosos de áreas diversas, como Carlos Franchi, João Wanderley Geraldi, Carlos Eduardo Uchôa, Ingedore Koch, Luiz Antônio Marcuschi, Rodolfo Ilari, Dino Pretti, José Carlos Azeredo, Maria Helena 
Moura Neves, Aparecida Lino Pauliukonis e José Luiz Fiorin, entre muitos outros, têm disseminado conceitos e metodologias aplicáveis ao ensino de língua que podem contribuir para melhorar o rendimento, considerado baixíssimo ${ }^{1}$, do alunado brasileiro.

Filiada a essa premência, na última década, também nós desenvolvemos pesquisas direcionadas, sobretudo, ao estudo de estratégias leitoras e à aplicação dessas estratégias ao desenvolvimento da competência linguageira nas aulas de língua materna, sempre com base nos postulados da Teoria Semiolinguística de Análise do Discurso, desenvolvida pelo professor Patrick Charaudeau (1992; 2008). Trata-se, por exemplo, de relacionar a diferença entre sentido de língua e sentido de discurso aos processos de compreensão e interpretação de textos, respectivamente, observados em exercícios de leitura no ensino fundamental (FERES, 2003). Também se trata de aplicar a noção de competência de linguagem às habilidades para construção do sentido, que se vinculam à análise da superfície textual em relação aos contextos discursivo e situacional, na leitura verbo-visual de livros infantis (FERES, 2006; 2010; 2011a; 2012; 2013). Ou ainda, de analisar o processamento analógico de sentido que produz um efeito patêmico em textos poéticos, utilizados em exercícios de interpretação realizados por universitários (FERES, 2010; 2011b). São contributos dos Estudos de Linguagem direcionados, pelo lado teórico, à compreensão da competência linguageira e, pelo lado prático, à formação dos leitores e dos professores de Língua Portuguesa.

Este trabalho pretende, em seguimento a essa linha de pesquisa, analisar mecanismos de produção de efeitos de sentido na textualização, seja por meio de emprego de representações de caráter patêmico (CHARAUDEAU, 2010), seja por meio da instauração da iconicidade (PEIRCE, 2003), nos três níveis de construção de sentido do texto: superficial, discursivo e situacional (CHARAUDEAU; MAINGUENEAU, 2004). Pressupõe-se que a programação de visadas de efeito é fundamentalmente discursiva e provoca como efeito não só o sentido (intelectivo) deduzido pela análise da relação entre conformação textual e as condições de uso do texto, mas também o sentimento, a reação afetiva/sensitiva às ideias e experiências suscitadas pela interação com o texto. Essa reação programada na textualização pode evocar a emoção subjacente a alguns signos de acordo com a valoração atribuída por um grupo, mas também pode utilizar a analogia, que se vale de uma qualidade comum a dois elementos, para evocar uma sensação, ou uma emoção. Como corpus, foram selecionados textos do poeta, compositor e artista multimídia Arnaldo Antunes e de livros ilustrados para crianças, de possível utilização em exercícios de interpretação no Ensino Básico.

Espera-se, com isso, contribuir para a compreensão dos fatores que constituem a competência de linguagem - essencial para a proficiência comunicativa -, assim como dar uma amostra de aplicação das noções elencadas neste estudo a textos que (também) utilizam a palavra escrita e que podem ser trabalhados na escola, especialmente na fase de consolidação da fluência em leitura, a fim de elucidar os mecanismos produtores dos sentidos (como efeitos) que dependem da relação entre a conformação textual e o contexto situacional-discursivo. Acredita-se que a análise discursiva dos textos pode ser

\footnotetext{
${ }^{1} \mathrm{O}$ resultado do último PISA, aplicado em 2012 e divulgado recentemente, mostra que o aluno brasileiro, ao final do ciclo fundamental, atinge nível 2 de leitura (numa escala de 6). No último ENEM, dos 784.830 participantes que indicaram, na inscrição, que fariam as provas para obter o certificado de conclusão do ensino médio, apenas 60.320 atingiram os requisitos mínimos de 450 pontos em cada uma das quatro áreas do conhecimento avaliada no exame e de 500 pontos na redação (numa escala de 1000 pontos). (Dados extraídos de http://portal.inep.gov.br, acesso em 15/01/2014.)
} 
tomada como uma leitura proficiente, capaz de apontar as relações necessárias para se atingir os sentidos emanados pela enunciação.

\section{COMPETÊNCIAS PARA "FAZER SENTIR"}

A Semiolinguística propõe um modelo de análise cuja perspectiva psicossociocomunicativa se vale, primordialmente, dos constituintes de uma troca, advindos de três níveis de construção de sentido (CHARAUDEAU, 2001; CHARAUDEAU; MAINGUENEAU, 2004): o nível superficial, em que operam as estratégias de tematização e de relação e em que podem ser observados os procedimentos combinatórios organizadores da textualidade; o nível discursivosemântico, em que são selecionados não só os procedimentos enunciatórios necessários a um específico modo de dizer, como o gênero textual e a modalização enunciativa, como também os saberes de conhecimento e de crença necessários para $o$ direcionamento semântico da combinatória materializada na superfície textual; por fim, o nível situacional, que justifica, em função dos papéis desempenhados pelos interagentes e do lugar enunciativo que ocupam, os propósitos do texto, de um lado, e, de outro, as expectativas e as finalizações testadas a partir da relação entre texto e uso.

Para Charaudeau, a competência de linguagem se compõe de "subcompetências" relativas a esses níveis de construção de sentido. É preciso ter habilidade para, ao observar a forma do texto e a organização de seus elementos constitutivos, criar expectativas de interpretação em função de restrições impostas pelo discurso, pelos modelos recorrentes de textualização e pelos saberes partilhados socialmente; além disso, para finalizar o sentido, torna-se fundamental considerar de que lugar (social) se diz/se interpreta o texto. Assim, a competência de linguagem se ajusta a uma determinação social e pragmática. Confirmados os sentidos criados em função dessa interseção, pode-se afirmar que houve habilidade suficiente para que o sujeito (comunicante ou interpretante) seja considerado competente.

Defende-se, porém, a existência de um outro tipo de competência, referente à construção de um sentido que, embora identificado e direcionado a uma realidade apreensível, não se pode denominar, ou significar de modo lógico, convencional, porque se refere a algo "indizível”, mas totalmente "passível de sentimento", de percepção. É a competência fruitiva (FERES, 2010; 2011a), que se conjuga às competências situacional, discursiva-semântica e semiolinguística e age analogicamente, por meio de uma "subsignificação" de base icônica, voltada para a exacerbação de qualidades e para o desencadeamento de sensações e emoções. Apesar de se ajustar às relações inferenciais estabelecidas nos e entre os três níveis de produção de sentido aos quais se referem as competências mencionadas, é uma competência diferenciada, que opera, fundamentalmente, a partir da percepção de qualidades e da aproximação de elementos similares. O "resultado interpretante" desse tipo de operação manifesta-se apenas no processo inferencial e funciona como um efeito de sentido, uma "provocação" de afetamento - sensível e reacional. Dessa maneira, pode-se considerar não exatamente um "novo" nível de construção de sentido em que trabalhe a competência fruitiva, pois, efetivamente, os elementos desencadeadores da fruição, dessa "percepção-significação sensível", transpassam os tais níveis mencionados, mas um modo específico de produção do "sentido-feeling", dependente das inferências afetivas que a conjuntura textual é capaz de suscitar. 
Como uma teoria de análise do discurso, em suas investigações, a Semiolinguística privilegia aspectos relacionados à socialização de práticas e de ideias como teor constitutivo dos enunciados e sua mise-en-scène - embora tenha como fundamento diferenciador o caráter comunicativo das trocas e a necessária observação da atuação dos sujeitos nela envolvidos. De acordo com essa orientação teóricoanalítica, Charaudeau $(2007,2010)$ explora um mecanismo discursivo específico para o desencadeamento de emoções: a patemização. Segundo o estudioso, há signos "portadores de emoções", em virtude de um "constituinte racional-reacional" que os torna propícios para suscitar emoções a partir de seu emprego. Mais do que se referir a emoções, esses signos acionam estados reacionais a partir do saber de crença partilhado por um grupo. Palavras como "desastre", "acidente", "terrorismo", ou imagens de catástrofes, de socorro a vítimas de um desmoronamento, por exemplo, podem ser usadas por causa de uma "visada acional" que busca promover um determinado estado emocional (previsível) no sujeito-destinatário. Além desse tipo de signo, é possível um texto veicular uma "visada patêmica" sem a presença de nenhum signo "patemizante", mas na referência a uma situação de enunciação marcadamente "emocionante".

\footnotetext{
A patemização pode, então, ser tratada discursivamente como uma categoria de efeito que se opõe a outros efeitos como o efeito cognitivo, pragmático, axiológico etc. E como toda categoria de efeito, ela depende das circunstâncias nas quais ela age. [...] O enunciado "é necessário matar esse cão" poderá ter um efeito cognitivo se se trata de uma palavra de um perito, um efeito pragmático para aquele que é responsável pela execução de tal tarefa, um efeito axiológico no que diz respeito à lei, e um efeito patêmico para o proprietário do cão.

É necessário, enfim, entrar nessa análise pelo "quadro de experiência" (como propõe Goffman), mas com uma teoria da situação. É aqui que o analista do discurso pode ser útil, na medida em que ele não se satisfaz em se valer somente de categorias linguístico-discursivas, e traz uma definição da troca comunicativa e uma metodologia para analisá-la. (CHARAUDEAU, 2010, p.39)
}

Dois pontos mencionados nessa citação precisam ser evidenciados. $\mathrm{O}$ primeiro é o tratamento da patemização como "categoria de efeito" que "depende das circunstâncias nas quais ela age"; o segundo, o papel do analista do discurso no tratamento desse recurso discursivo estreitamente ligado aos constituintes situacionais da troca comunicativa. Como desdobramento desses pontos, pode ser citada uma maior predisposição de certos "dispositivos comunicativos", justamente por causa da finalidade de cada troca: os dispositivos de comunicação ficcional e midiática, assim como as discussões polêmicas, por razões diferentes, estariam mais suscetíveis ao desencadeamento de emoções do que, por exemplo, os dispositivos de comunicação científica e didática. "Quando o dispositivo se predispõe, é porque a finalidade se encontra sob a forte dominante captadora e que os parceiros estão 'envolvidos' nos saberes de crença" (CHARAUDEAU, op.cit., p.40). Soma-se a isso o fato de o campo temático em que se apoia o dispositivo comunicativo pode prever um universo de patemização e propor certa organização dos imaginários sociodicursivos propícia a esse efeito, além de a instância de enunciação precisar se valer de uma mise en scène discursiva com "visada patemizante". 


\section{2 "FAZER SENTIR" COM A (NÃO)VERBALIDADE}

Embora o sistema linguístico demonstre um funcionamento "orgânico" autossuficiente, no que respeita à referência, não se pode deixar de considerar aspectos discursivos e situacionais vinculados à enunciação: se uma palavra significa algo, significa em função do lugar que ocupa no sistema linguístico, mas, sobretudo, em função do lugar enunciativo em que se coloca; significa algo naquela situação de comunicação, de acordo com os coenuciadores envolvidos no processo e com as coerções socializadas pelo uso por determinado grupo.

Assim, pode-se afirmar que o signo verbal se funda, por um lado, numa possibilidade estabilizada pelo sistema linguístico e, por outro, numa factualidade flexibilizada e relativizada por um uso específico, por um "eu/tu-aqui-agora". Quanto mais geral e "transparente" for o uso, mais estável e previsível o conteúdo veiculado pelo signo; quanto mais específico for esse uso, mais flexível e relativa passa a ser a significação, mais dependente dos saberes que circundam a enunciação e emanam do próprio uso, e não da estabilidade do sistema.

Além disso, não se pode deixar de considerar dois outros aspectos indissociáveis da significação: a força das relações analógicas que embalam o processamento simbólico e a relação inequívoca entre o verbal e o não verbal, em meios mono ou multimodais. $\mathrm{O}$ primeiro aspecto torna-se imprescindível para a compreensão de certas estratégias inferenciais (principalmente afetivas); o segundo aspecto, complementar ao primeiro, é essencial para a compreensão da imaginação no processamento dos sentidos.

Postulando-se que um signo - como tal - só passa a existir quando comunica um sentido, e que o sentido depende de uma dose de materialidade comunicante, outra de possibilidade de reconhecimento por um determinado grupo social e mais uma de entendimento de sua intencionalidade em função do uso por determinados interagentes, é preciso observar as circunstâncias de sua emergência a fim de compreender a complexidade de sua constituição.

Peirce (2003; SANTAELLA, 2005; SANTAELLA e NÖTH, 2005) explica o processo significativo a partir de uma relação triádica: um signo representa um objeto num interpretante. A relação significante/significado estaria, pois, limitada por um "resultado" interpretante, justificado pelo ponto de vista de onde parte a significação.

\footnotetext{
Um signo, ou representâmen, é aquilo que, sob certo aspecto ou modo, representa algo para alguém. Dirige-se a alguém, isto é, cria, na mente dessa pessoa, um signo equivalente, ou talvez um signo mais desenvolvido. Ao signo assim criado denomino interpretante do primeiro signo. $O$ signo representa alguma coisa, seu objeto. Representa esse objeto não em todos os seus aspectos, mas com referência a um tipo de ideia que eu, por vezes, denomino fundamento do representâmen. (PEIRCE, 2003, p.46)
}

Essa tríade que instaura a significação ainda estaria submetida ao tipo de relação entre o signo e o objeto, o que determinaria, inclusive, a genuinidade do processo: quanto mais convencional essa relação, mais genuíno o signo (denominado "símbolo", nesse caso); quanto mais motivada, ou, em outras palavras, quanto mais regida pela semelhança entre signo e objeto, menos genuíno o signo (considerado, então, um "ícone"); se baseada em uma relação por contiguidade, o signo, já 
correspondendo a uma reação significativa, estaria, então, entre o genuíno e o motivado (tem-se, no caso, um "índice").

Em outras palavras, a significação, como "resultado interpretante" na mente de quem opera a significação, pode se dar não só pelo acionamento de uma relação entre significante e significado, estabelecida arbitrariamente e convencionada por um grupo social, mas também por uma relação estabelecida motivadamente, por uma relação de semelhança entre o que se apresenta e o que isso representa, ou, ainda, por uma relação parte-todo, ou causa-efeito, de aproximação de pontos de contato entre os componentes da significação, em se tratando de signo verbal ou não verbal. Embora anterior aos estudos relativos à enunciação, a teoria peirciana abriga, portanto, a influência de aspectos "ambientais" no interior do próprio processo significativo.

A significação deve ser caracterizada como um processo multifacetado, constituído por todo tipo sígnico, por variado mecanismo, em razão de cálculos interpretativos que dependem, por um lado, daquilo que é conhecido (até convencionalmente) e, por outro, daquilo que é perceptível a partir do processamento em si. O caráter perceptivo é conduzido, quase sempre, pela apreensão de qualidades e pela similaridade entre signo e objeto. Desse modo, em diferentes graus de convenção e/ou de motivação, a significação é capaz de lidar com processamentos mais lógicos, ou mais analógicos; mais objetivos, ou mais subjetivos; mais previsíveis, ou mais inusitados; mais intelectivos, ou mais afetivos; mais ordinários, ou mais extraordinários. Em cada ativação, o signo se presta a representar e/ou a apresentar aquilo que substitui limitada e perspectivadamente.

A presença do não verbal (leia-se "não significável pela palavra", mas por uma imagem, por um diagrama, pela plasticidade, pelo gestual, sonoro, tátil, gustativo, pela prosódia) é constatada em todo processo significativo, seja na apresentação mesma do signo, quando não revestido (pelo menos não exclusivamente) de verbalidade, seja no acionamento, por meio de inferências intelectivas e/ou afetivas, de resultados interpretantes "não simbolizáveis", mas “indicáveis" ou "imitáveis". É preciso lembrar que, mesmo presos à verbalidade, outros (vários) meios - factual ou virtualmente substitutivos da realidade representada - são a ela associados a fim de lhe "completar o sentido". E as inferências dependem, sobretudo, de associações ligadas às percepções, à capacidade de qualificação (perceptiva-sensorial, ou mediada pela cultura), e não a uma "simbolização referencial" objetiva, destituída de valores instituídos sensitiva ou socialmente.

$\mathrm{Na}$ materialidade do signo, o caráter não verbal pode ser representado por traços, cores, gestos, sons, cheiros e até gostos, inclusive em situações em que pode ou não haver "emitente humano": o desenho de um cão numa placa revela sua presença em dado ambiente, atentando para a periculosidade própria desse animal; a dupla verde-eamarelo numa bandeira representa a nacionalidade brasileira; o dedo em riste próximo à boca significa silêncio; o som de uma sirene é um aviso; o cheiro do gás de cozinha é um índice de sua presença com a finalidade de prevenir acidentes; o mau gosto do leite pode significar que ele está estragado; a presença de nuvens indica a possibilidade de chuva.

Ainda partindo da materialidade, pode-se aludir a uma não verbalidade conjugada à verbalidade. Mesmo a pontuação, necessária até ao registro escrito mais estabilizado e aparentemente distanciado de uma relação estreita com particularidades advindas da enunciação em si, como num manual de instruções, por exemplo, busca reproduzir constituintes paraverbais, como os prosódicos e entoacionais (KERBRAT- 
ORECHIONI, 2010), também acrescentando aspectos que, embora intimamente relacionados à verbalidade, ultrapassam seu sistema de regras. Além disso, gêneros textuais estáveis como os manuais, caracteristicamente claros e objetivos, não excluem a construção de simulacros descritivos e explicativos, utilizando, muitas vezes, imagens esquemáticas e diagramas como elementos cotextuais, num engajamento multimodal que também depende da não verbalidade.

De outro modo, à materialidade do signo podem subjazer elementos não verbais igualmente significativos, apenas evocados pela textualidade e presentificados por meio da imaginação. Sensações podem ser suscitadas, por um lado, pela referência simbólica (leia-se "por meio da palavra", "signo genuíno", cuja relação significado/significante se funda essencialmente na arbitrariedade) a elementos da natureza e do mundo; por outro, por estratégias como escolhas lexicais carregadas de sobreposições de qualidades. Num movimento de "retaguarda", aciona-se a experimentação "virtual" das sensações de uma cena apenas evocada, pela combinação entre palavras, imaginação e sensibilidade.

As palavras não apenas significam - intelectivamente - "realidades", mas seu arranjo ajuda a (re)construir "mundos" multidimensionais, impregnados de experiências palatáveis, recuperados daquilo que certo grupo social entende como valor positivo/negativo, certo/errado, dogmático ou discutível. Esse arranjo ancorado a uma historicidade comunica e dissemina ideias sempre passíveis de qualificações. E as qualificações, assim como as qualidades, embora muitas vezes sejam filtradas pela cultura, são da ordem do sensível (e memorável), e não do meramente racionalizável; por conseguinte, se valem daquilo que extrapola a sistematização linguística; são vivenciáveis - ainda que virtualmente.

Os aspectos até aqui selecionados se mostram ainda bastante presos à própria materialidade do signo, mas há outros igualmente importantes, como aqueles vinculados ao processamento cognitivo do significado, na operação mesma que institui o sentido para determinado item que está por alguma outra coisa, numa relação substituinte. Mesmo a expressão mais objetiva guarda em si itens que se apoiam em imagens e semelhanças, ou em qualidades constitutivas de seu significado, como se comprova, inclusive, na análise das metáforas conceituais: se VIDA É CAMINHO, então "Vou seguir em frente" (LAKOFF; JOHNSON, 2002). Não há significação que se exima do não verbal, ainda que se pondere quanto ao grau componencial de sua atuação nesse processo. Mas é nas relações analógicas, fundadas, sobretudo, na aproximação dos elementos por similaridade (existente, ou instituída por correspondência), que reside uma força impregnada de sentidos, sensações, sentimentos. A partir das associações por semelhança, é possível não só representar (ainda que "degeneradamente") algo supostamente "indizível", como também colocar em evidência uma qualidade em função de um propósito - comunicativo, ou pragmático.

Em "Linguística e comunicação", Jakobson (s/d) já examinava e exaltava o papel fundamental da teoria peirciana sobre a significação, especialmente no que tange à motivação sígnica. Após tratar de diversos tipos sígnicos (como permite pensar uma teoria não somente linguística), a fim de esclarecer as bases da Semiótica Peirciana, o linguista russo elenca uma longa série de argumentos factuais com que pretende demonstrar a (impressionante) presença da relação motivada entre significado e significante, salientando seu aspecto icônico: “...esforcemo-nos agora para examinar a estrutura linguística sob seu aspecto icônico e propor uma resposta à questão suscitada por Platão: em virtude de que espécie de imitação (mimêsis) a língua liga o significante 
e o significado?" (JAKOBSON, [s/d], p.104). Segundo ele, há um "caráter diagramático", de "natureza icônica", que sustenta muitos mecanismos linguísticos, como se percebe, por exemplo, nos graus de comparação dos adjetivos nas diversas línguas indo-europeias, que apresentam um crescimento gradual do número de fonemas em função da própria gradação dos significados (high - higher - highest; altus - altior altissimus).

Mais adiante, Jakobson trata das funções da linguagem e, de modo especial, da função poética da linguagem, cujo estudo "deve ultrapassar os limites da poesia, e, por outro lado, o escrutínio linguístico da poesia não se pode limitar à função poética". Quando predominante em um texto, essa função pode ser identificada pela explicitude das relações associativas que também organizam os signos constituintes do texto.

A seleção [de palavras] é feita em base de equivalência, semelhança e dessemelhança, sinonímia e antonímia, ao passo que a combinação, a construção da sequência, se baseia na contiguidade. A função poética projeta o princípio da equivalência do eixo de seleção sobre o eixo da combinação. A equivalência é promovida à condição de recurso constitutivo da sequência. (JAKOBSON, [s/d], p.130)

Como se constata, vislumbra-se, na superfície do texto com predominância da função poética, a associação "por equivalência" que, em outros tipos de textos, normalmente permanece apenas implícita. É possível, portanto, perceber a colocação de signos em relação por causa de certas qualidades que os tornam "equivalentes". Ao colocar "à mostra" essa relação, automaticamente focaliza-se a superfície textual, dessa forma mais "opaca" e relativamente "autorreferencial": "como" se diz significa tanto quanto "o que" se diz. Esse recurso "poético" é explorado sempre que se objetiva uma mais contundente força expressiva, como em anúncios publicitários, em conversas ordinárias plenas de emoção, em jingles de campanha política, entre outros, e em textos literários, com investimento estético.

Pignatari (2004, p.10) afirma que "o poeta não trabalha com o signo, o poeta trabalha o signo verbal"; "ele vive o conflito signo vs. coisa. Sabe (isto é, sente o sabor) que a palavra 'amor' não é o amor - e não se conforma" (Op.cit., p.11). E ainda: "O poema transmite a qualidade de um sentimento. Mesmo quando parece estar veiculando idéias, ele está é transmitindo a qualidade do sentimento dessa idéia. Uma idéia para ser sentida e não apenas entendida, explicada, descascada" (Op.cit, p.18). Com isso, podese afirmar que o poeta (entenda-se aí não só aquele que maneja o signo verbal, mas aquele que deixa transparecer, por meio da forma, um sentido sentido) tenta acabar com esse "desapego" entre as palavras e as "coisas" (ou os signos e aquilo que representam), apresentando o que é sensível por meio daquilo que é inteligível.

\section{VISADAS DE EFEITO PATÊMICO: A TEORIA NA PRÁTICA}

O processo de "fazer sentir" (emoção, ou sensação evocadas) pode ser analisado a partir da extremidade da produção, como processo de implicitação, de planejamento da conjunção entre forma e contexto para produzir efeitos, ou, a partir da extremidade da interpretação, como processo inferencial, de "extração" de sentidos, ou cálculo dos sentidos implícitos. Neste trabalho, assumindo a postura da Teoria Semiolinguística de Análise do Discurso, privilegia-se a observação das visadas de efeito tais como instauradas no texto em função de sua intencionalidade e em sua 
latência, e não como resultado produto do processo de interpretação, mas como um resultado previsível e deliberadamente projetado. Para análise dos mecanismos patêmicos, serão abordados exemplos extraídos de textos poéticos de Arnaldo Antunes, oriundos de uma antologia $(1996 ; 2002)$ e de livros ilustrados para crianças criados por Ziraldo (2005; 2009; 2010) e por Elisa Lucinda (2010). Em cada elemento analisado, será evidenciado o nível de construção de sentido de onde incide prioritariamente a produção do efeito - embora se saiba que qualquer cálculo de sentido parta da forma, da superfície textual, em sua relação com o contexto e se conclua com um resultado que é suscitado como efeito, ou seja, o sentido finalizado é sempre um efeito de sentido, latente, programado pela textualização, mas apenas provável, constituído por implícitos que se juntam aos explícitos.

No livro "Palavra Desordem" (2002), Arnaldo Antunes investe na reconstrução de lexias simples e complexas (palavras, expressões, clichês, ou ditos populares), cuja diagramação singular - cada qual em uma página inteira, utilizando as mais diversas direções - acrescenta-lhes efeitos de sentido. Na reconstrução, o estranhamento provoca a alusão ao sentido correspondente à nova forma - iconicamente.

"EXCESSÍSSSISSSSISSSSSIMO" (ANTUNES, 2002, p.168): a própria palavra apresenta o excesso que expressa. A aplicação do sufixo superlativo -íssimo (que por si só expressa intensidade, ou abundância) à base substantiva EXCESSO, cujo significado é redundado pelo sufixo num quase espelhamento significativo, provoca-se a exacerbação da qualidade de SER EXCESSIVO. Além disso, a repetição das sílabas e das consoantes, aproveitando-se da aliteração e sugerindo alongamentos (que também significam intensidade, ou abundância), também provoca, iconicamente, pelo excesso de elementos, não só a ideia que se quer comunicar, mas, sobretudo, a sensação daquela qualidade. A interpretação no nível superficial/formal, a fim de se estabelecer o sentido intelectivo, é permeada pelo sentimento (ato de sentir) daquele excesso. A ocupação de todo o espaço da página corrobora essa sensação.

Já em "REJUVELHECER" (ANTUNES, 2002, p.187), percebe-se a sobreposição de palavras (REJUVENECER/REJUVELHECER), possibilitada pela semelhança sonora, e a formação da palavra-valise. Com isso, une-se, iconicamente, a condição de "ser jovem" à de "ser velho" e, ao aproximar esses elementos, assemelhaos, e/ou mistura-os. A modificação operada no nível superficial, ligada a mecanismos linguísticos, faz aflorar uma questão própria do nível discursivo, bastante debatida na atualidade: a ideia da "eterna juventude", mesclada às campanhas de valorização da "melhor idade", influenciadas pela evolução da qualidade de vida na terceira idade. Ou ainda, o simples questionamento existencial daquele que envelhece, sentindo-se ainda jovem. De qualquer forma, emerge uma discussão partilhada socialmente, oriunda das relações estabelecidas com o contexto social, por meio da neologia, da analogia e daquilo que os elementos formadores fornecem como representações com "visada patêmica", já que impregnadas de valores socialmente partilhados. O posicionamento descendente, nesse caso, também pode estabelecer um vínculo com essa visada, se for considerado um saber de crença que avalia negativamente o processo natural de envelhecimento (ratificada pela metáfora conceptual MENOS É PARA BAIXO).

Em “ABRE-TE CÉREBRO” (ANTUNES, 2002, p.32), a conhecida frase “Abre-te, Sésamo!", repetida na história de "Ali Babá e seus quarenta ladrões" como fórmula mágica para a abertura da caverna onde se guardava o fruto dos roubos dos bandidos, é subvertida. A semelhança sonora entre as duas expressões ressalta a analogia localizada no nível discursivo em função da intertextualidade, já que trabalha 
com um conhecimento prévio de domínio de um grupo social determinado e para o qual aponta o sentido saliente - mais frequente e familiar - da expressão fossilizada, ali também reconhecida, mas transformada. "Abre-te cérebro" é o resultado de uma integração conceitual sobreposta à expressão-origem, e figura um apelo quanto à "abertura do cérebro", ou melhor, à "expansão da mente". Esse conteúdo é resultado de uma interpretação por meio de uma implicatura, isto é, uma infração "programada" ao princípio de cooperação que rege as trocas comunicativas (GRICE, 1979). No caso, infringe-se a máxima da qualidade, que postula não se poder dizer nada contrário à realidade dos fatos, sob a pena de tornar o enunciado ininteligível. Um conhecimento prévio mínimo impede de se considerar a abertura do cérebro - literalmente - ou por causa da iminência de morte diante dessa ação, ou porque não seria previsto um contexto, por exemplo, de necropsia, em que esse procedimento poderia ser aventado em primeiro plano. Assim, o entendimento da expressão migra para um sentido que é mais abstrato, porém que usufrui da concretude dos elementos constitutivos do original (por isso chamado de "figurado"), que tem "mente" por "cérebro", e "expansão" pelo ato de "abertura". O aspecto mais interessante, além dos procedimentos icônicos já mencionados (semelhança sonora entre as expressões; semelhança semântica entre os termos), é o que excede o limite intelectivo, transportando para a nova expressão a qualidade essencial da frase originária: seu caráter mágico. Ainda que não seja dito, ao se operar a sobreposição dos enunciados, esse, que é um constituinte "colateral", passa, ao apelo agora configurado, seu teor "mágico", sobrenatural. Nessa hereditariedade qualificadora, a emergência da qualidade da atitude evocada se oferece à apreensão.

Há relações icônicas mais intimamente ligadas ao nível situacional de construção de sentido. Nesse caso, as circunstâncias de enunciação determinam a finalização dos sentidos, seja pelo peso do papel social assumido pelo sujeito enunciador, ou projetado para o sujeito-destinatário, seja pela influência da historicidade constitutiva do texto sobre o cálculo interpretativo. No exemplo seguinte, a canção "Desce" (ANTUNES, 1996 - faixas 8 e 12), pode ser observado o emprego de estratégias de afetamento, baseadas na iconicidade, que, por um lado, explora os papéis sociais de que se impregnam os coenunciadores-personagens do texto e, por outro, o "tom performático" da enunciação:

desce do trono, rainha

desce do seu pedestal

de que vale a riqueza sozinha,

enquanto é carnaval?

desce do sono, princesa

deixa o seu cetro rolar

de que adianta haver tanta beleza

se não se pode tocar?

hoje você vai ser minha

desce do cartão postal

não é o altar que te faz mais divina

deus também desce do céu

desce das suas alturas 
desce da nuvem, meu bem

por que não deixa de tanta frescura

e vem para a rua também?

No circuito "interno" de que participam as personagens, de acordo com o momento/lugar da enunciação, (“enquanto é carnaval"), o eu lírico, sujeito-enunciador, interpela uma mulher posicionada superiormente e faz um pedido insistente ("desce do trono, rainha/desce do seu pedestal"). O acionamento desses papéis - o "folião" e a "rainha" - só é possível no reconhecimento desse circuito, como participantes da cena enunciativa do carnaval; fora dela, esses papéis não existem. A interpelação "impositiva", da maneira como se realiza, também só é possível na situação comunicativa que coloca um folião "de rua" na condição de questionar uma "rainha do carnaval" e argumentar: "de que vale a riqueza sozinha/enquanto é carnaval?"; "de que adianta ter tanta beleza/se não se pode tocar?"; "não é o altar que te faz mais divina". Ao longo da interpelação, infere-se o posicionamento "altivo" do enunciador que justificaria a "impertinência" da petição: "desce do sono, princesa" deixa subentender a inutilidade da ilusão efêmera daquele momento, assim como "desce das suas alturas/desce da nuvem, meu bem" e "deixa de tanta frescura" tentam persuadir a interlocutora a participar com o folião do carnaval "da rua", "do chão", já que, fora daquela situação, poderiam pertencer ao mesmo nível hierárquico (em termos de papéis discursivos).

A canção é apresentada, no $\mathrm{CD}$, em duas versões: na primeira, imprime-se à voz e ao violão, acompanhados por violinos e contracanto melancólicos, um tom extremamente grave e um andamento bastante lento; na segunda, o tom é bem mais alto e o andamento passa a ser o de uma verdadeira marchinha de carnaval e, além disso, a voz é acompanhada por percussão e por um coro quase gritado. Isoladas as versões, pode-se dizer que a primeira enunciação faz emergir um "sentido" triste, arrastado; já a segunda, a alegria. Aproximando as versões a partir de suas semelhanças (a música e a letra), percebe-se o contraste entre os tons evocados e pode-se interpretar a mudança como a transformação do estado de espírito do enunciador: primeiro, abatido, e depois, quase debochado, após a superação do abatimento. No circuito externo de que participa o sujeito-enunciador-cantor/músico (que também assume a personagem e participa do circuito interno) e o sujeito-interpretante-ouvinte (que não participa da cena, mas "assiste-a" imaginativamente), tanto o entendimento das versões, quanto o sentimento emanado por elas são planejados para afetar o ouvinte/interpretante no momento de sua enunciação, de acordo com o propósito de cada conformação. São sentidos que se agregam ao das palavras, mas são emanados pelos timbres, tons, performances, colateralmente.

A interseção entre os níveis de construção do sentido direciona a interpretação de qualquer texto e deve ser observada, sobretudo, nos exercícios de leitura mediada, como recurso interpretativo fundamental. No caso do texto multimodal próprio dos livros ilustrados para crianças, a complementaridade de que participam frequentemente diferentes universos sígnicos quase sempre obriga um vínculo motivado entre expressão e conteúdo a fim de se estabelecer a unidade textual, assim como de provocar a ludicidade - e esse vínculo tem uma natureza fundamentalmente poética. Além disso, a figurativização característica do gênero literatura infantil, de essência analógica, exige a ratificação dessa correspondência — muitas vezes a partir de uma simbologia estereotipada intrínseca ao gênero; outras, a partir de cálculos interpretativos mais 
complexos, dependentes da apreensão desse vínculo motivado. Frequentemente, esses livros apresentam forma narrativa com duplo endereçamento (a criança e o adulto, este quase sempre mediador da leitura), que pode manifestar graus variados de complexidade constitutiva, seja pelo tipo de integração entre a linguagem verbal e a visual, seja pela presença ou não de um narrador que "preenche lacunas" de mais difícil solução por parte das crianças, não acostumadas com a lógica narrativa, ou com o léxico variado.

Não se pode negligenciar a força da representação imagética quanto à inclusão de sentidos ao projeto textual do livro ilustrado como um todo, comprovando, assim, sua parcela constitutiva numa conformação genuinamente verbo-visual. Embora não se preste tanto quanto o signo verbal para refinar e hierarquizar categorias, ou dar um tratamento abstrato ao propósito do texto, é justamente seu processamento analógico que permite "dizer o indizível", apresentando sentidos mais do que os representando, a partir de relações entre signo e objeto, ou entre elementos (inter)textuais, baseadas na similaridade. Com as analogias, ou com o processamento icônico, torna-se possível "concretizar o abstrato". Ao aproximar elementos por uma semelhança (inerente ou instituída), a qualidade que os une é exacerbada e, assim, por uma inferência fundada na percepção, ou na qualificação dos seres, é também provocado o efeito "sentido", "afetivo". Além das representações já propensas a uma reação emotiva por causa de um caráter patêmico pré-discursivo, a significação por analogia permite, atrelada a seu caráter "original" (na acepção de Peirce, como "origem de uma qualidade"), a programação de emoções e sentimentos por meio do inusitado. A representação de caráter patêmico não consegue realizar esse tipo de programação.

Ainda que a semiose verbal difira da visual em vários aspectos, muitas regras antes só estudadas em relação ao signo verbal mostram-se produtivas em relação ao não verbal e, mais precisamente, ao visual, como as noções de coesão e de coerência textual, ou ainda a de representação patemizante. As diferenças mais marcantes são a obrigatória disposição linear do texto verbal e a dupla articulação do signo de acordo com um sistema apriorístico de que participa, contra a disposição holística do texto imagético e seu sistema heurístico, inaugurado na conformação do enunciado (embora também se discuta uma gramática do visual, cf. KRESS e LEEUWEN, 2006). Além disso, é relevante, principalmente para a investigação aqui engendrada, por exemplo, o papel atribuído às imagens que ultrapassam a simples identificação referencial e alçam a simbolização convencional (BARTHES, 1990). Soma-se a essa "convencionalidade lógica" própria do verbal, que se estende ao visual, um movimento inverso: o processamento analógico, fundamentalmente imagético, se espraia até o lógico nas metáforas, por exemplo. Enfim, embora de natureza diversa, a semiose verbal e a visual apresentam recursos comuns que as identificam, ou, pelo menos, as aproximam, e, em sua diferença fundamental, se complementam em vários aspectos.

Ser poético, em termos de materialidade textual, pode corresponder a ser diferente, estranho, interessante, único; é produzir uma combinação incomum de formas que se assemelham (de algum modo) e "obrigar" a percepção do processo de seleção, sempre curioso, desafiador, original. Por exemplo, em Flicts (ZIRALDO, 2009, p.11), que trata da história de uma cor-personagem sem lugar no mundo, a frase "Era apenas/o frágil e/feio/e aflito/Flicts, a aliteração (que evidencia a combinação incomum de formas que se assemelham por causa da sonoridade) não só acentua a identificação do personagem Flicts com características depreciativas (frágil, feio e aflito), como também, 
ao reiterar o som fricativo lábio-dental como o de quem bufa, remete o estado de ânimo do personagem à ideia de desconforto, rejeição, esmorecimento.

Da mesma maneira atuam os neologismos criados por Ziraldo (2005, p.11, 14, 20, respectivamente) em Uma historinha sem (1) sentido, ao tratar das aventuras de um super-herói que sucumbe por não ter o "poder da leitura": zip-zap-urgência, zzzzressonando, tchan-distância, entre outros exemplos. São também combinações incomuns de formas que se assemelham, neste caso, nas relações entre a onomatopeia e a palavra que a acompanha: aquela corrobora a expressão do significado desta a partir da situação que evoca com sua sonoridade: zip-zap (em "[o herói] precisava, com uma zip-zap-urgência, acender a luz para poder localizar-se") remete à situação de rapidez, de premência, como algo que vai e volta correndo, produzindo o som representado pela onomatopeia; zzzz (em "Então apagou a luz do quarto e logo, logo já estava zzzressonando") imita o som do ressonar e já é fórmula cristalizada pelas histórias em quadrinhos para representar alguém dormindo, ressonando; tchan (em "tomou uma tchan-distância, avançou para a porta escolhida e, como um raio, atravessou-a, veloz") está vinculado ao suspense, como forma abreviada de trecho da sinfonia de Beethoven, usada como fundo musical para situações de medo e, no caso, da distância a ser saltada.

Em O menino mais bonito do mundo (2010), de forte intertextualidade com o Livro bíblico do Gênesis, a apresentação das imagens e sua forma de significar provocam inúmeras inferências, apoiadas em informações extratextuais. Ao comparar a imagem que marca o fato narrativo inicial à imagem que constitui o começo do clímax da história, percebem-se os mesmos elementos imagéticos, mas construídos diferentemente, numa acréscimo significativo relevante para o enredo: na primeira, a árvore, o sol, as montanhas apresentam traços infantis e cores primárias; já na segunda, traços firmes, detalhados e cores pastéis. A referência ao "Menino" é substituída, nesse momento pela referência ao "Homem". O contraste desses elementos e a relação entre as imagens e o conhecimento a respeito de como pessoas de diferentes faixas etárias desenham, infere-se não só a visão de uma criança e, depois, de um adulto, mas, consequentemente, o amadurecimento desse ser.

Em todos os casos aqui mencionados, o sujeito falante transmutado em descritor, intervém e produz efeitos "visados" (possíveis, planejados). Nomear, localizar-situar e qualificar são os componentes, autônomos e indissociáveis do modo de organização descritivo (CHARAUDEAU; 2008). Tanto as expressões nominais (ligadas à descrição das personagens, por exemplo), quanto as imagens revelam, nas analogias produzidas, representações fortemente marcadas social e culturalmente, cujo entendimento se submete à apreciação de valores e crenças partícipes de um constructo cultural orientador do leitor inexperiente a que se expõe o texto.

Em outro livro ilustrado, A menina transparente, que faz parte da Coleção Amigo Oculto (Editora Record) e, em outros livros da mesma coleção, a personificação de um conceito (no caso, "poesia"), é concretizada em uma textualização versificada de autoria de Elisa Lucinda (2010) e ilustrada "poeticamente" por Graça Lima. A interpelação ao "leitor-modelo" por parte da personagem-narradora tem o intuito de produzir um efeito de "brincadeira de adivinhação", característica da coleção de que o livro participa. As ilustrações apresentam imagens codificadas e metáforas visuais e se configuram de maneira complementar em relação à parte verbal dos textos (NIKOLAJEVA; SCOTT, 2011; HUNT, 2010).

No livro em análise, a descrição da personagem é organizada cataforicamente, a fim de que a nomeação dos entes personificados - e a consequente identificação do 
conceito selecionado como tema - ocorra apenas no término de sua descrição. Além disso, observa-se a iconicidade como processo significativo predominante, atuando como um desencadeador de significações por meio de analogias instituídas, muitas vezes, a partir de saberes de crença.

A descrição/definição de poesia, dificultada pelo alto grau de abstração do conceito, a princípio ganha contornos de acordo com uma imaginária localização de sua manifestação. Os espaços mencionados são variados, mas têm em comum a incongruência dessa variedade (pôr do sol/asa de gaivota/ar/mar/comida na panela/livro/vestido de notas musicais), que transporta a interpretação para a não concretude de sua essência. São espaços que se revestem de uma valoração positiva e convidativa, imbuindo a poesia de um caráter "romântico", tomado como prototípico. Além disso, a poesia é apresentada, em sua "transparência", ou na "invisibilidade" de sua existência, como algo perceptível através dos elementos nos quais adere - "Eu apareço disfarçada de todas as coisas..." (LUCINDA, 2010, p.1) -, desde que ela inspire um olhar diferenciado: "Tem gente que diz que eu/ Nasço dentro da pessoa,/E faço ela olhar diferente/ Pra tudo que todos olham,/ Mas não notam" (Op.cit., p.3). A natureza evanescente é sua principal qualidade: "Às vezes apareço tão transparente e de mansinho/Que mais pareço um Gasparzinho./Tem gente que nunca percebe que estou ali,/Não cuida de mim,/Não me exercita./Eu fico como um laço de fita/Que nunca teve um rabo de cavalo dentro" (LUCINDA, 2010, p.5).

A aproximação da personagem Gasparzinho, o "fantasminha camarada" que habita imaginário tanto do grupo social que produz o livro, quanto daquele a quem se destina, transporta as qualidades de ser transparente, evanescente, "irreal", metafísico, imaterial à delimitação do conceito em questão. A ideia de um fantasma, em geral considerada uma representação que desencadeia medo, é desvinculada desse sentimento pela subversão trazida pela personagem de fácil identificação no universo infantil, pois se trata de um "fantasma-criança", alegre, com bons sentimentos, que deseja ter amigos e não assustar ninguém. A menção a Gasparzinho, portanto, inclui muitas informações que dizem respeito ao imaginário sociodiscursivo do qual o leitor participa. Já a comparação com o "laço de fita que nunca teve um rabo de cavalo dentro", assim como faz referência a elementos relacionados ao universo infantil, também revela a qualidade de ser abstrato, dependente de um elemento outro por meio do qual possa se manifestar e provar sua função: o laço de fita, ornamento e instrumento, só existe quando exerce o papel de prender um rabo de cavalo. O laço de fita não está tão presente nos penteados das meninas de hoje, mas faz parte do imaginário social que o vincula à infância e que o perpetua como símbolo de feminilidade.

Quanto às ilustrações, toma-se a como exemplo a de uma menina negra (a mesma da capa do livro), com asas e arco e flecha, que faz referência a Cupido, deus do amor, e representa a poesia. A renda compõe seu vestido e seu cabelo. As "flechas" lançam as palavras poesia, sol, amor, viver e nomes de poetas, como Manoel de Barros, Drummond, Cecília Meireles, Cora Coralina. Peixes, passarinhos, libélulas, borboletas e flores seguem-na, num voo guiado por ela. A constante presença das rendas nas ilustrações simboliza o romantismo, a delicadeza e a leveza atribuídos à poesia, além de caracterizarem sua brasilidade, tão marcada pelo artesanato de onde se originam as rendas. A referência ao Cupido por meio do arco e da flecha de onde saem as palavras codifica a ilustração, conferindo-lhe uma significação reconhecida para além da individualidade da imagem, a partir de saberes partilhados culturalmente. Os nomes lançados pelas flechas são representações impregnadas de valoração positiva e 
relacionada à própria noção de poesia que se mostra querer difundir, valoração essa passível de reconhecimento pelo grupo, desde que os parceiros envolvidos na troca comunicativa engendrada pelo livro tenham acesso a esses saberes. Para o leitor menos experiente, a mediação da leitura operada por um leitor "maduro" é imprescindível, não só para a construção do sentido orientado pelo texto, mas também para a difusão desses símbolos e desses valores. Esses são saberes amparados pela cultura e por uma perspectiva específica que se disseminam, sobretudo, por meio de materiais simbólicos tais como os livros.

As metáforas - verbais e visuais - igualmente se estabelecem a partir desse aparato cultural. Domínios e ideias são sobrepostos em função de uma similaridade patente ou instituída. Por exemplo, o enunciado "Sou uma criança com muitos pais" (LUCINDA, 2010, p.3), aproxima criança e poesia, a quem se refere a declaração. Para isso, é preciso se estabelecer um elo a partir de algo em comum, uma qualidade que as une e que é salientada por essa mesma união. Da criança, extrai-se a qualidade de ser inaugural, ou original, possível atributo também para a poesia, ideia corroborada pelos versos: "E faço ela [a pessoa] olhar diferente/Pra tudo que todos olham,/Mas não notam" (Op.cit., p.3). Da mesma forma, a menina-cupido e a poesia são aproximadas pelo caráter difusor de emoções e isso se percebe visualmente, tanto pelas asas e pelo arco e flecha, que a assemelham ao Cupido, como pela direção das palavras que saem do arco, a mesma para a qual aponta a flecha. Os seres que a seguem formam com ela um conjunto similar a um cardume e revelam os elementos constitutivos da poesia, seja representando a natureza em sua diversidade (pássaros, peixes, flores), que costuma lhe servir de tema, seja despertando valores positivos atrelados a esses elementos (contemplação, emoções positivas, beleza).

Em A menina transparente, soma-se às simbologias já consolidadas a ideia inclusiva que traz a negritude para participação igualitária não só da sociedade, assim como do imaginário sociodiscursivo que se constrói a partir de então, e que permite subentender novos valores. Destaca-se a utilização de várias personagens negras, como a própria menina-cupido, a quem se vinculam qualidades consideradas positivas, além de ela mesma representar a poesia em si. No caso dessa personagem, subverte-se, primeiro, a ideia trazida pelo anjo como símbolo, por ter sido ali representado não só pelo gênero feminino, mas também por uma menina negra e que, além disso, extrapolando a condição de menina e de negra, age como um cupido, disseminador de "sensibilidades".

\section{ENTRE 0 DIZÍVEL E 0 INDIZÍVEL}

Inseridos numa realidade programada pela cultura, "lemos" sem parar; atribuímos sentido às experiências de acordo com uma subjetividade parcialmente partilhada pelo social. Segundo Bizzocchi (2001), “percepção e interpretação ideológica da realidade implicam um duplo processo de filtragem da informação potencial existente no meio. O real é filtrado primeiro pelos nossos sentidos (filtragem biológica) e, a seguir, pela nossa cultura (filtragem ideológica)." Ainda que se considere que a leitura propriamente dita, ou a leitura do texto verbal escrito, exija uma habilidade decodificadora específica, não se pode negligenciar o contributo "extratextual" necessário à interpretação, presente em qualquer ato de construção de sentido. Em outras palavras, leitura é tarefa que pressupõe, em qualquer de suas dimensões, habilidade para perceber e fazer relações a partir do ponto de vista do sujeito que 
interpreta. Só é capaz de ler quem se coloca como partícipe do processo dinâmico de construção de sentido; já quem é colocado para repetir o outro não se torna capaz de ler, nem de aprender a aprender.

Morin (2008) defende que, à oferta de grande quantidade de informações fragmentadas, é preferível o conhecimento, nascido da observação, da relação entre dados, do questionamento e, quem sabe, um conhecimento transformado em sabedoria: focaliza-se uma parcela da realidade, percebe-se sua forma, relaciona-se essa forma a conteúdos já conhecidos; percebe-se o novo, o desconhecido; questiona-se o novo, desconfia-se dele; investe-se a subjetividade daquele que interpreta, seu lugar social de origem, sua experiência e seus saberes e, enfim, constroem-se sentidos, criticamente. Assim, aprende-se algo. A consciência dos mecanismos de implicitação/inferenciação de sentidos e efeitos pode levar o leitor (em seu sentido mais amplo) a "aprender a aprender" com autonomia, criatividade e criticidade. Por isso, defende-se a formação dos leitores (ou seja, de leitores já em desenvolvimento) e dos formadores de novos leitores, a fim de que se alargue a possibilidade de entendimento do mundo e das coisas, da manipulação de informações e das emoções, não intuitivamente (como a falta de orientação específica leva a crer), mas conscientemente, no domínio das estratégias de dizer e de não dizer.

Em "Discurso das mídias", Charaudeau (2007) relaciona o problema da interpretação como é tratado na escola e a "visão ingênua" que muitas vezes acomete os meios de comunicação de massa quando tratam da "informação":

(...) modelo perfeitamente homogêneo, objetivo, que elimina todo efeito perverso da intersubjetividade constitutiva das trocas humanas, e identifica a comunicação com a informação e esta com um simples procedimento de transmissão de sinais. (CHARAUDEAU, 2007, p.35)

Na nota de rodapé, ele registra sua crítica com a seguinte digressão: “O mesmo ocorre com certa concepção do sistema educativo que postula que o aluno é capaz de compreender e não coloca o problema da interpretação". A "interpretação" como "problema" precisa ser considerado tema de debate e de apropriação teórica por aqueles que fazem da Educação seu propósito profissional. A "interpretação" exige investimento pessoal na construção do sentido; subjetividade, autoria, posicionamento. Já a compreensão rasa e repetida é mais "fácil" e só precisa do eco involuntário e inconsciente daqueles que perpetuam "certezas", preconceitos e irreflexão.

Construir sentido é, segundo Charaudeau (2008), sempre uma aposta acerca dos saberes partilhados pelos interlocutores - saberes esses muito mais vastos do que o conhecimento do sistema linguístico, espraiados pela cultura e pelo contexto situacional em que se insere cada texto. Aguçar a sensibilidade leitora para a interpretação é uma aposta ainda maior, por causa, de um lado, da inclusão do investimento cognitivo do interlocutor na construção dialógica do sentido textual e, de outro, da (necessária) conscientização das estratégias textuais e discursivas a qual pode tornar o leitor não só mais fluente, como também crítico, mais defeso contra as manipulações.

\section{REFERÊNCIAS BIBLIOGRÁFICAS}

ANTUNES, Arnaldo. Palavra desordem. São Paulo: Iluminuras, 2002. 202 p. . CD O silêncio, BMG,1996. 
BARTHES, Roland. O óbvio e o obtuso. Rio de Janeiro: Nova Fronteira, 1990.

BIZZOCCHI, Aldo. Cognição: como pensamos o mundo. Ciência Hoje, v. 30, n. ${ }^{\circ}$ 175, setembro de 2001, p. 34-40.

CHARAUDEAU, Patrick. Grammaire du sens et de l'expression. Paris: Hachette, 1992.

. De la competencia social de comunicación a las competencias

discursivas. In: Revista interamericana de estudios del discurso - ALED, Venezuela:

Editorial Latina, volume I, número 1, p. 7-22, agosto de 2001.

. O discurso politico. São Paulo: Contexto, 2006.

. O discurso das mídias. São Paulo: Contexto, 2007.

2008.

. Linguagem e discurso: modos de organização. São Paulo: Contexto,

. A patemização na televisão como estratégia de autenticidade. In:

MENDES, Emília; MACHADO, Ida Lúcia (orgs.). As emoções no discurso, volume II. Campinas, SP: Mercado de Letras, 2010. p. 23-56.

; MAINGUENEAU, Dominique. Dicionário de Análise do Discurso. São Paulo: Conmtexto, 2004.

FERES, Beatriz dos Santos. A escola "faz questão" de leitores autômatos ou autônomos? A atividade de leitura no ensino fundamental. Niterói-RJ, 2003. Dissertação (Mestrado em Letras). Programa de pós-graduação em Letras da Universidade Federal Fluminense.

- Competência para l/ver Ziraldo: subsídios teóricos para a formação de leitores. Niterói-RJ, 2006. Tese (Doutorado em Letras). Programa de Pós-graduação em Letras da Universidade Federal Fluminense.

. Competência para ler com emoção. In: MENDES, Emília; MACHADO, Ida Lúcia (orgs.). As emoções no discurso, volume II. Campinas, SP: Mercado de Letras, 2010. p.123-140. EdUFF, $2011 \mathrm{a}$.

Leitura, fruição e ensino: com os meninos de Ziraldo. Niterói-RJ:

. O tempo em Arnaldo Antunes. In: Anais do IX Congresso Latinoamericano de Estudos do Discurso (ALED): Belo Horizonte, MG. 2011b.

Mia Couto, Marilda Castanha, Chico Buarque e Ziraldo: o medo como efeito de sentido em livros ilustrados. In: ARAÚJO, Rodrigo da C.; WILBERT, O. (orgs.) Literatura infantojuvenil: diabruras, imaginação e deleite. Vila Velha, ES: Opção Editora, 2012a. p. 67-88. 
. A Qualificação Implícita no Livro Ilustrado “A Princesa Desejosa”. In:

Signum: Estudos Ling., Londrina, n. 15/3 (esp), p. 129-147, dez. 2012 b.

. A verbo-visualidade a serviço da patemização em livros ilustrados. In:

Bakhtiniana, São Paulo, 8 (2): 90-105, Jul./Dez. 2013.

FIORIN, José Luiz. Teorias do discurso e ensino da leitura e da redação. In: Gragoatá. Niterói, RJ: EdUFF, volume 2, número 1, p.7-28, 2.sem.1996.

GRICE, H. P. Logique et conversation. In: Communications $n^{\circ}{ }^{30}$. Paris: Seuil, 1979.

HUNT, Peter. Crítica, teoria e literatura infantil. São Paulo: Cosac Naify, 2010.

JAKOBSON, Roman. Linguística e comunicação. 2.ed. São Paulo: Cultrix, s/d. 162p.

KERBRAT-ORECHIONI, C. Pour une analyse multimodale des interactions orales:l'expression des émotions dans les débats politiques télévisuels. In: Cadernos de Letras da UFF: Dossiê Letras, linguística e suas interfaces. Niterói-RJ, 2010, v.40, p.17-45, agosto de 2010 .

KRESS, Gunther; LEEUWEN, Theo van. Reading images: the grammar of visual design. 2.ed. New York: Taylor \& Francis e-Library, 2006.

LAKOFF, G. e JOHNSON, M. Metáforas da vida cotidiana. Campinas, SP: Mercado de Letras; São Paulo: EDUC, 2002.

LUCINDA, Elisa. A menina transparente. Ilustr.: Graça Lima. Rio de Janeiro:

Galerinha Record, 2010.

MORIN, Edgar. A cabeça bem-feita: repensar a reforma, reformar o pensamento. 15.ed. Rio de Janeiro: Bertrand Brasil, 2008.

NICOLAJEVA, M.; SCOTT, C. Livro ilustrado: palavras e imagens. São Paulo: Cosac Naify, 2011.

PEIRCE, Charles S. Semiótica. 3.ed. São Paulo: Perspectiva, 2003.

PIGNATARI, D. O que é comunicação poética. 8.ed. Cotia - São Paulo: Ateliê Editorial, 2004.

SANTAELLA, Lúcia. Matrizes da linguagem e pensamento: sonora, visual, verbal. 3.ed. São Paulo: Iluminuras: FAPESP, 2005.

Paulo: Iluminuras, 2005. ;NÖTH, Winfried. Imagem: cognição, semiótica, mídia. 4.ed. São 
SENNA, Luiz Antônio G. Letramento ou leiturização? O sócio-interacionismo na Lingüística e na Psicopedagogia. In: Anais do $12^{\circ}$ Congresso de Leitura do Brasil. Campinas/SP, Associação de Leitura do Brasil, 2000. p. 3203-3225. Disponível em http://www.senna.pro.br/biblioteca/leiturizacao_new.pdf.

ZIRALDO Alves Pinto. Uma historinha sem (1) sentido. 2.ed. São Paulo: Melhoramentos, 2005.

. Flicts. 64.ed. São Paulo: Melhoramentos, 2009.

. O menino mais bonito do mundo. São Paulo: Melhoramentos, 2010.

Recebido em: 17 de fevereiro de 2014.

Aprovado em: 19 de maio de 2014. 